\title{
Molecular Basis of Citrus sunki Susceptibility and Poncirus trifoliata Resistance Upon Phytophthora parasitica Attack
}

\author{
Ronaldo José Durigan Dalio, ${ }^{1}$ Heros José Máximo, ${ }^{1}$ Tiago Silva Oliveira, ${ }^{1}$ \\ Thamara de Medeiros Azevedo, ${ }^{3}$ Henrique Leme Felizatti, ${ }^{2}$ Magnólia de Araújo Campos, ${ }^{3}$ and \\ Marcos Antonio Machado', ${ }^{1,}$ \\ ${ }^{1}$ Biotechnology Lab, Centro de Citricultura Sylvio Moreira. Cordeirópolis-SP, Brazil; ${ }^{2}$ Instituto de Matemática, Estatística e \\ Computação Científica, Universidade de Campinas, Campinas-SP, Brazil; and ${ }^{3}$ Universidade Federal de Campina Grande, \\ Cuité-PB, Brasil
}

Accepted 7 November 2017.

\begin{abstract}
Coevolution has shaped the molecular basis of an extensive number of defense mechanisms in plant-pathogen interactions. Phytophthora parasitica, a hemibiothrophic oomycete pathogen and the causal agent of citrus root rot and gummosis, interacts differently with Citrus sunki and Poncirus trifoliata, two commonly favored citrus rootstocks that are recognized as susceptible and resistant, respectively, to $P$. parasitica. The molecular core of these interactions remains elusive. Here, we provide evidence on the defense strategies employed by both susceptible and resistant citrus rootstocks, in parallel with $P$. parasitica deployment of effectors. Time course expression analysis (quantitative real-time polymerase chain reaction) of several defense-related genes were evaluated during i) plant disease development, ii) necrosis, and iii) pathogen effector gene expression. In $C$. sunki, $P$. parasitica deploys effectors, including elicitins, NPP1 (necrosis-inducing Phytophthora protein 1), CBEL (cellulose-binding elicitor and lectin activity), RxLR, and CRN (crinkler), and, consequently, this susceptible plant activates its main defense signaling pathways that result in the hypersensitive response and necrosis. Despite the strong plant-defense response, it fails to withstand $P$. parasitica invasion, confirming its hemibiothrophic lifestyle. In Poncirus trifoliata, the effectors were strongly expressed, nevertheless failing to induce any immunity manipulation and disease development, suggesting a nonhost resistance type, in which the plant relies on preformed biochemical and anatomical barriers.
\end{abstract}

Citrus fruit and juice are consumed worldwide and are produced in more than 140 countries, with China (24.4\%), Brazil $(15.64 \%)$, and the United States $(7.75 \%)$ representing the main

Ronaldo José Durigan Dalio and Heros José Máximo contributed equally to this work.

Funding: This work was supported by Fundação de Amparo à Pesquisa do Estado de São Paulo (FAPESP) grant numbers 2008/57909-2, 2014/50880-0, and 2015/14498-6 and by Conselho Nacional de Ciência e Tecnologia (CNPq) grant numbers 573848/2008-4.

${ }^{\dagger}$ Corresponding author: Marcos Antonio Machado;

E-mail: marcos@ccsm.br

*The $e$-Xtra logo stands for "electronic extra" and indicates that 12 supplementary figures and one supplementary table are published online.

(C) 2018 The American Phytopathological Society producers (FAO 2015). Over the years, however, the citrus industry has been suffering the impact of many biotic and abiotic stress conditions. Several diseases caused by a diverse range of viruses, bacteria, fungi, oomycetes, and nematodes have led to the annual loss of millions of dollars, which globally compromises the economy and food security (Dalio et al. 2017). In addition to the use of chemical defensives and fertilizers, a frequent management strategy in citrus against different stresses is the use of suitable rootstocks, such as 'Sunki' mandarin (Citrus sunki Hort. Ex Tan.) and trifoliate orange (Poncirus trifolita (L.) Raf. cv. Rubidoux). C. sunki rootstocks have demonstrated tolerance to drought, salinity, citrus tristeza disease, citrus blight, and citrus sudden death, whereas Poncirus trifoliata has been tolerant to low temperatures, nematodes, Phytophthora spp., as well as citrus tristeza disease and citrus sudden death (Boava et al. 2011). Accordingly, both species have been extensively used in genetic breeding programs for the production and selection of hybrids, known as citrandarins, which possess the desired features of the parental cultivar (Siviero et al. 2006).

Microbes maintain a long-standing interaction with plants, which may be either a parasitic or mutualistic relationship (Cuming 2009). During evolution, the molecular basis of plantmicrobe interactions has constantly changed and has molded the mechanisms of plant defense (Cuming 2009; Gilbert and Parker 2016). These dynamic changes include both immediate and long-term responses, such as transcriptional gene reprogramming, production of metabolites, and genome stability and epigenetic alterations (Boyko and Kovalchuk 2011). At the front line, plant defenses rely on the structural and chemical barriers that are constitutively produced to prevent pathogen entrance (Malinovsky et al. 2014). At the second line, plants set a complex network of signaling pathways that encompass microbe perception and subsequent defense activation (Zhang et al. 2013).

A coevolutionary model of plant-pathogen interaction has been established that depicts different layers of plant immune response and pathogen attack (Jones and Dangl 2006). In the first layer, plants perceive conserved pathogen-associated molecular patterns (PAMPs) by their pattern recognition receptors (PRRs) and induce PAMP-triggered immunity (PTI). Generally, PTI results in an influx of $\mathrm{Ca}^{2+}$ into the plant cytosol (known as a $\mathrm{Ca}^{2+}$ burst), production of extracellular reactive oxygen species (ROS), protein phosphorylation, protein kinases activation, and modulation of defense-related phytohormones, such as salicylic acid (SA), jasmonate (JA), and ethylene (ET) (Bigeard et al. 2015). Successful pathogens are able to overcome PTI by secreting 
effector molecules into one or both the apoplast and cytoplasm of the host plant cells (Cui et al. 2015). The effector molecules modulate the plant physiology and innate immunity, which leads to a state known as effector-triggered susceptibility (ETS) (Kazan and Lyons 2014; Lo Presti et al. 2015). Therefore, pathogens and effectors play an important role as selective agents in host plant populations (Chisholm et al. 2006; Karasov et al. 2014).

Plants with resistance $(R)$ genes, whose products recognize the pathogen effectors, are able to acquire an immunity condition named effector-triggered immunity (ETI) (Thomma et al. 2011). During ETI, plant defenses are prolonged in comparison with the responses triggered by PTI, being generally characterized by plant cell death surrounding the infection site, known as the hypersensitive response (HR), and induction of systemic acquired resistance (SAR) in host plants (Kushalappa et al. 2016). These pathogen effectors are fast-evolving molecules, which results in derivative forms of an 'ancient' effector; consequently, recently evolved effectors may either gain new molecular activities, no longer be impaired, or both by a host $\mathrm{R}$ protein, presented in a previous resistance plant (Marín et al. 2013). This evolutionary event generates another layer of ETS that continuously evolves in a dynamic way (Cui et al. 2015).

During pathogenic infection, distinct phytohormones can be induced and act as signal molecules to trigger the production of antimicrobial compounds (Verma et al. 2016) in an intricate, orchestrated, and interactive network (Verhage et al. 2010). Typically, plants produce SA, JA, and ET as major defense signals upon pathogen attack (Robert-Seilaniantz et al. 2011); however, plants also deploy other mechanisms to counteract pathogen attack, and such strategies include the production of a range of phenolic compounds, defensins, protease inhibitors, hydrolytic enzymes, ROS, and phytoalexins (Ahuja et al. 2012; HaraNishimura and Hatsugai 2011; Kim et al. 2009; Lacerda et al. 2014; Tripathy and Oelmüller 2012).

Several Phytophthora species threaten citrus production worldwide, and the most important species are $P$. citricola Sawada, P. citrophthora (R. E. Sm. \& E. H. Sm.) Leonian, P. drechsleri Tucker, P. palmivora (E. J. Butler) E. J. Butler, and $P$. parasitica Dastur (=P. nicotianae). Due to its vast distribution and pathogenicity, $P$. parasitica is considered the main citrus oomycete pathogen, causing citrus gummosis and citrus root rot diseases (Panabieres et al. 2016). P. parasitica is an aggressive soil-borne pathogen with a fast growth rate and hemibiothrophic lifestyle and rapidly colonizes roots and stems of susceptible citrus species.

Among citrus, C. sunki is a highly susceptible rootstock, whereas Poncirus trifoliata is considered resistant or tolerant to P. parasitica (Boava et al. 2011); however, the physiological and molecular mechanisms behind citrus susceptibility or tolerance are still poorly characterized. Cytological studies have showed extensive pathogen colonization in roots and leaves of susceptible Arabidopsis thaliana, with formation of abundant haustoria-like structures (Attard et al. 2014; Wang et al. 2011). A. thaliana mutant lines with compromised SA, JA, and ET signaling pathways have shown increased susceptibility to $P$. parasitica, demonstrating the relevance of these phytohormones to plant defense and suggesting that components of phytohormone signaling pathways may be potential targets of pathogenic effectors. Accordingly, Evangelisti et al. (2013) reported that the $P$. parasitica RxLR penetrating specific effector 1 (PSE1) targets auxin-related signals to impair $A$. thaliana physiology, thus enabling infection. Attard et al. (2014) found that RxLR effectors are differentially expressed during the necrotrophic stage of infection in A. thaliana.

To date, several apoplastic effectors have already been reported to modulate citrus physiology (Khatib et al. 2004; Oßwald et al. 2014), including the elicitin ParA1 (Kamoun et al. 1993), the necrosis and ethylene-inducing peptide (NEP1-like protein), the necrosis-inducing Phytophthora protein 1 (NPP1) (Fellbrich et al. 2002), and the cellulose-binding elicitor and lectin activity (CBEL) effectors. However, the expression dynamics of cytoplasmic effectors such as RxLR and crinklers (CRN) are still to be determined during citrus- $P$. parasitica interaction.

Here, we aimed to address the following scientific questions. i) Does the pathogen colonize both $C$. sunki and Poncirus trifoliata tissues? ii) Do both citrus species recognize the pathogen attack and activate their defense systems? iii) If so, which genes and signaling pathways are activated by each species? iv) Does $P$. parasitica deploy different sets of effectors depending on the host? Hence, understanding the molecular interactions and finding the key components that mediate Poncirus trifoliata tolerance and $C$. sunki susceptibility may contribute to the development of alternative strategies to control $P$. parasiticainducing disease, such as targeted genetic breeding, host-induced gene silencing, and cisgenic plants.

\section{RESULTS}

\section{C. sunki and Poncirus trifoliata exhibit} contrasting responses upon $\boldsymbol{P}$. parasitica infection.

Seedlings of $C$. sunki and Poncirus trifoliata were inoculated with $P$. parasitica zoospores and disease progression was examined. $C$. sunki plants developed severe symptoms of leaf wilt and root rot at $96 \mathrm{~h}$ postinoculation (hpi); in contrast, no symptoms were observed in Poncirus trifoliata seedlings (Fig. $1 \mathrm{~A}$ to $\mathrm{C}$ ). To confirm that infection was effective in both species despite the lack of symptoms in Poncirus trifoliata, we were able to re-isolate $P$. parasitica from $C$. sunki and Poncirus trifoliata roots (Fig. 1D and E), indicating the presence of either viable reproductive structures, hyphae, or both on root tissues.

Indeed, $P$. parasitica mycelia were visualized in the root cortex and sporangia were observed, as well, in roots of $C$. sunki (Fig. 2). These observations were consistent with the high levels of $P$. parasitica DNA present in $C$. sunki-inoculated roots (Fig. 3B). P. parasitica growth in the root tissues of $C$. sunki was confirmed by linear regression statistical analysis (Fig. 3C). On the other hand, none of $P$. parasitica structures were observed in Poncirus trifoliata seedlings under light microscopy (Fig. 2B, $\mathrm{D}$, and F), although $P$. parasitica genomic DNA still could be retrieved from infected roots but decreased over time (Fig. 3C). No hyphae, mycelium, or $P$. parasitica DNA were found in control plants (Figs. 2 and 3 ).

This opposite growth behavior of $P$. parasitica in each citrus species is thoroughly represented in Figure 3, illustrating the amount of $P$. parasitica genomic DNA measured in both species, showing an increase in $C$. sunki and a decrease in Poncirus trifoliata roots over the time-course experiment. These findings assure the assumption of $C$. sunki susceptibility and Poncirus trifoliata resistance to $P$. parasitica infection.

\section{SA-, JA-, and ET-mediated defenses do not contribute to citrus resistance against $P$. parasitica.}

To gain insights into the defense mechanisms of susceptible (C. sunki) and resistant (Poncirus trifoliata) citrus plants upon $P$. parasitica infection, we evaluated the expression of genes related to the major plant defense pathways, i.e., SA, JA, and ET, in addition to genes related to basal immunity and other physiological processes.

Quantitative real-time polymerase chain reaction (RT-qPCR) analyses were carried out in $P$. parasitica-infected roots sampled at 3, 6, 12, 24, 48, and 96 hpi (Figs. 4, 5, and 6; Supplementary Figs. S1 through S7). $P$. parasitica infection induced transcriptional reprogramming of the major defense pathways in C. sunki (Figs. 4 and 6). Most of the genes exhibited slight 
increases at 3 and $6 \mathrm{hpi}$, returning to basal expression level at $12 \mathrm{hpi}$, then a peak of upregulation at $24 \mathrm{hpi}$, followed with a slight upregulation 48 hpi onwards. The majority of SA-related genes, which were herein evaluated, showed induction during all sampled timepoints, with the greatest changes observed for Heat Shock Protein90 (HSP90) and REQUIRED FOR MLA12 RESISTANCE 1 (RARl) genes. Similar patterns were detected for genes that participate in JA and ET signaling pathways (Fig. 6) and for $R$ genes and genes related to oxidative burst and HR, which were all also up-regulated. Despite the differential expression of plant immunity-related genes, Aquaporin1 gene expression (strongly associated with physiology of healthy plants) did not alter at early timepoints and only showed slight downregulation at $96 \mathrm{hpi}$, which indicates that the plant immunegene expression could be independent of the normal physiologic gene expression. Likewise, we tested five candidate housekeeping genes for both citrus species during infection, and these all received high scores, on NormFinder and geNorm software programs (Máximo et al. 2017), to also indicate a detached expression pattern of defense-related genes and normal physiologic genes. Intriguingly, Poncirus trifoliata exhibited constitutive levels for most of the defense-related genes that were evaluated (Fig. 5), suggesting that either this citrus species does not recognize this pathogenic organism or this plant defense resistance does not involve activation of those immunity-related genes.

Generally, plants face a trade-off between growth and defense. After pathogen recognition, plants close stomata, which decreases water uptake and photosynthesis, reallocating most of the energy supply to fight the pathogenic attack (Gudesblat et al. 2009). Here, the water uptake rates decrease in a linear pattern for both citrus species, but in $C$. sunki-infected plants, the water uptake rate is $0.91 \%$ higher than in $C$. sunki control plants ( $t$ test $P$ value, 0.0049). In Poncirus trifoliata, an inverse behavior was observed, with infected plants showing statistically significant difference of $-0.80 \%$ compared with noninoculated plants ( $t$ test $P$ value, 0.0467379). Poncirus trifoliata actively decreased its water consumption from $24 \mathrm{hpi}$ onwards (Fig. 7), indicating that, in spite of the lack of defenserelated gene activation, Poncirus trifoliata was able to recognize $P$. parasitica attack and adjusted its own physiology. On the other hand, $C$. sunki increased water uptake at 24 hpi and maintained its consumption above control plants. This result can be explained either by decreased hydric potential in $C$. sunki roots, due to the release of more solutes to the tissues after pathogen infection and tissue necrosis, or by the action of pathogen effectors that manipulate plant hormone signaling pathways (Evangelisti et al. 2013).

\section{C. sunki produces ROS for defense against $P$. parasitica.}

Several genes related to oxidative burst and HR were upregulated in $C$. sunki-infected plants. To check if this increase would, indeed, result in release of ROS and, consequently, oxidative burst, we performed diaminobenzidine tetrahydrochloride (DAB) staining in root samples, infected or not, of both plant species. DAB is oxidized by hydrogen peroxide and generates a dark brown precipitate-the browner the stains in the tissues, the more ROS were released. Thus, $C$. sunkiinfected roots appeared darker than Poncirus trifoliata-infected roots, as did both infected tissues compared with noninfected control plants (Fig. 8).

The DAB assay confirmed our hypothesis that a strong increase of defense-related genes would result in oxidative burst and, ultimately, necrosis (Fig. 1B). This robust plant defense response would be an effective strategy against biotrophic pathogens; however, it was not sufficient to prevent $P$. parasitica growth and colonization (Fig. 3), most likely because $P$. parasitica, as a hemibiotrophic pathogen, is well-adapted to both "trophic" conditions.

\section{Putative $P$. parasitica effector genes are expressed} during interaction with $C$. sunki and Poncirus trifoliata.

It could also be speculated that the root microenvironment, including root exudates and cell-wall fragments, could interfere with effector expression of $P$. parasitica, resulting in differences in susceptibility and resistance found for the plants. We tested the hypothesis that $P$. parasitica interacts with Poncirus trifoliata by secreting few effectors in a mild intensity, while C. sunki would be overwhelmed with higher levels of the pathogen effectors. To shed light on this issue, we evaluated the expression of several $P$. parasitica candidate effectors, either
A

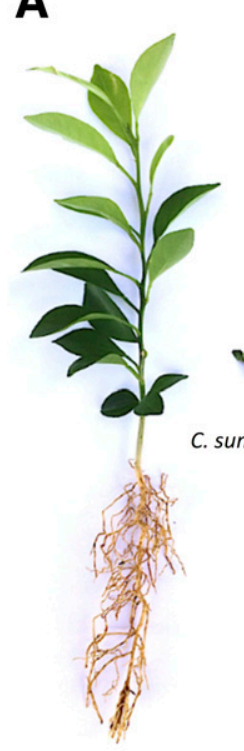

control

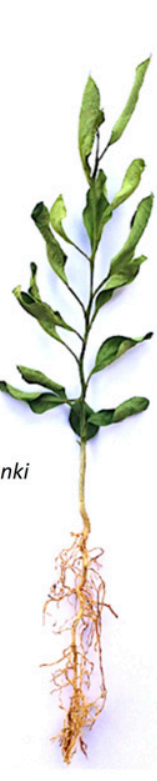

infected

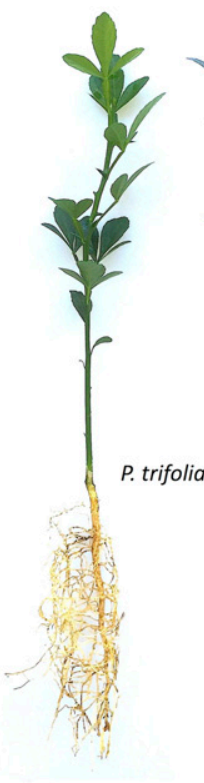

control

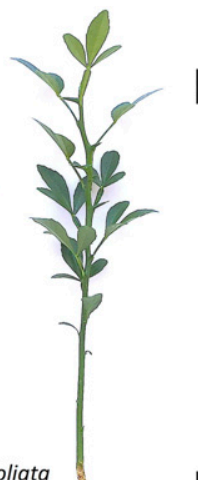

D
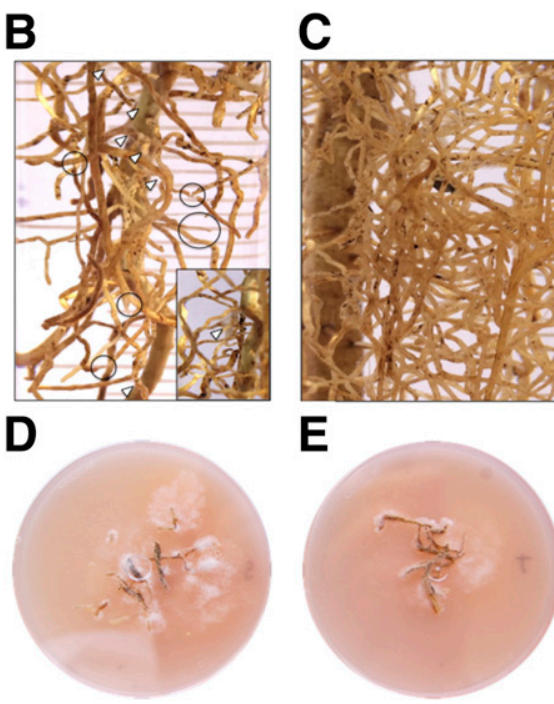

E

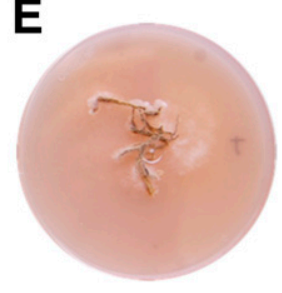

Fig. 1. Citrus sunki and Poncirus trifoliata plants, infected with Phytophthora parasitica and control noninfected, sampled at 96 h postinoculation. A, Wilt leaves in infected C. sunki. B and C, Roots of infected C. sunki and Poncirus trifoliata. Arrows and circles indicate mycelia and root rot, respectively. D and E, Plates containing selective medium to reisolate P. parasitica from C. sunki and Poncirus trifoliata. 
apoplastic or cytoplasmic, during interaction with both citrus species.

Most candidate effector genes were up-regulated in both plants, which rejects our initial hypothesis (Figs. 9 and 10); however, their expression pattern was distinct between samples from each of the infected plants, as we expected. In $C$. sunki, some gene expressions were decreased, e.g., $P p C R N 4$, which was down-regulated at all timepoints, and $P p C R N 8$, which had decreased expression at 6
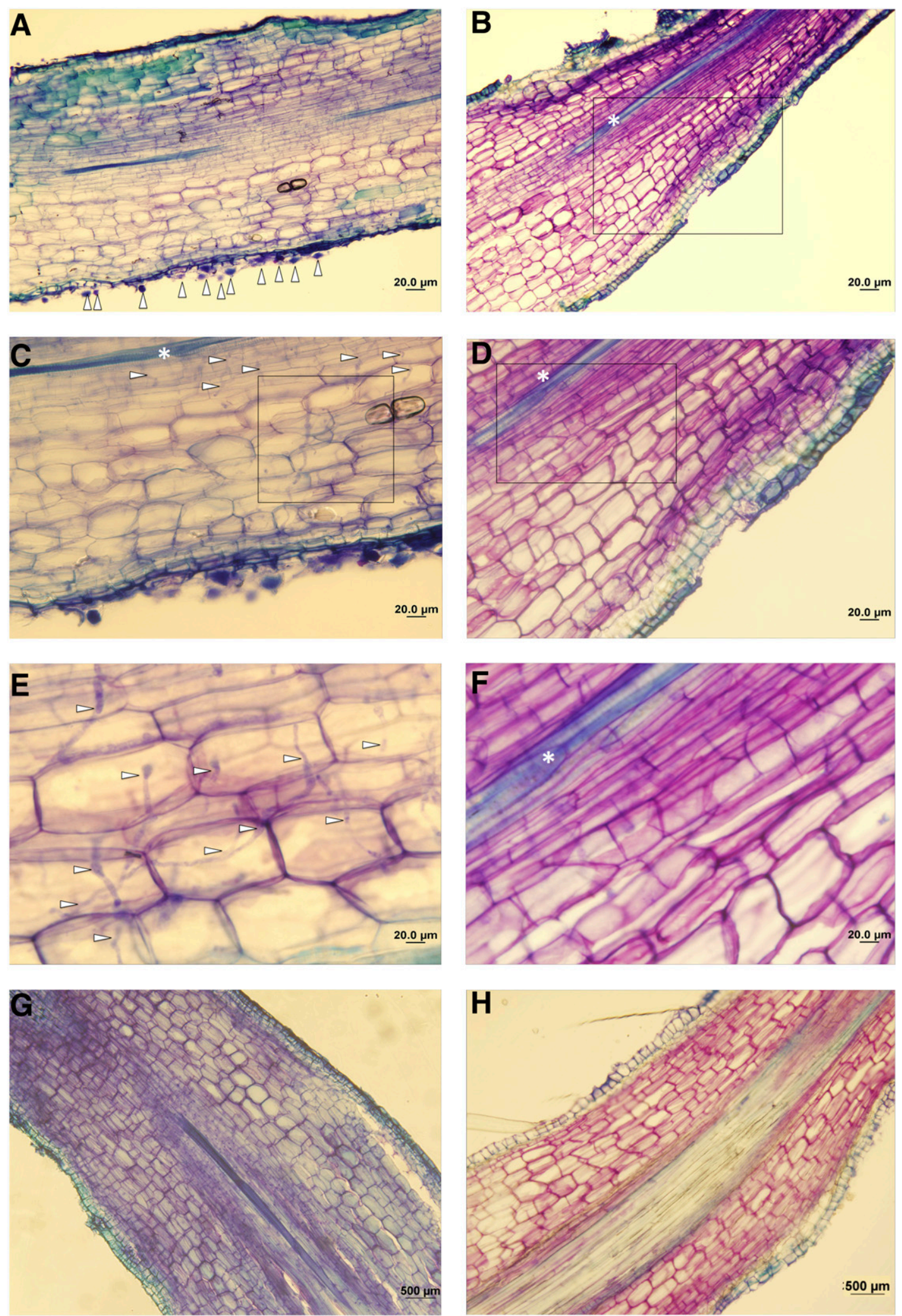

Fig. 2. A to F, Phytophthora parasitica-infected plants sampled at $96 \mathrm{~h}$ postinoculation and $\mathbf{G}$ to $\mathbf{H}$, noninoculated control plants. E, Magnified view of infected C. sunki, with arrows indicating P. parasitica hypha. F, Magnified view of infected Poncirus trifoliata without apparent oomycete growth. Longitudinal sections of Citrus sunki root tips are shown in A, C, E, and G and of Poncirus trifoliata in B, D, F, and H. Samples were stained with toluidine blue and were observed under light microscope. 


\begin{tabular}{|c|c|c|c|c|c|c|c|}
\hline \multirow{2}{*}{$\mathbf{A}_{\text {Scale }}$} & \multirow[b]{2}{*}{ C. sunki } & & & \multicolumn{2}{|c|}{ (DNA $\mu \mathrm{g} / \mathrm{g}(\mathrm{FW}))$} & & \\
\hline & & 1,16 & 0,86 & 1,51 & 1,03 & 3,48 & 2,39 \\
\hline \multirow{2}{*}{0} & time course & $3 \mathrm{hpi}$ & 6 hpi & 12hpi & 24hpi & $48 \mathrm{hpi}$ & $96 \mathrm{hpi}$ \\
\hline & P. trifoliata & 0,77 & 0,39 & 0,32 & 0,43 & 0,08 & 0,31 \\
\hline
\end{tabular}

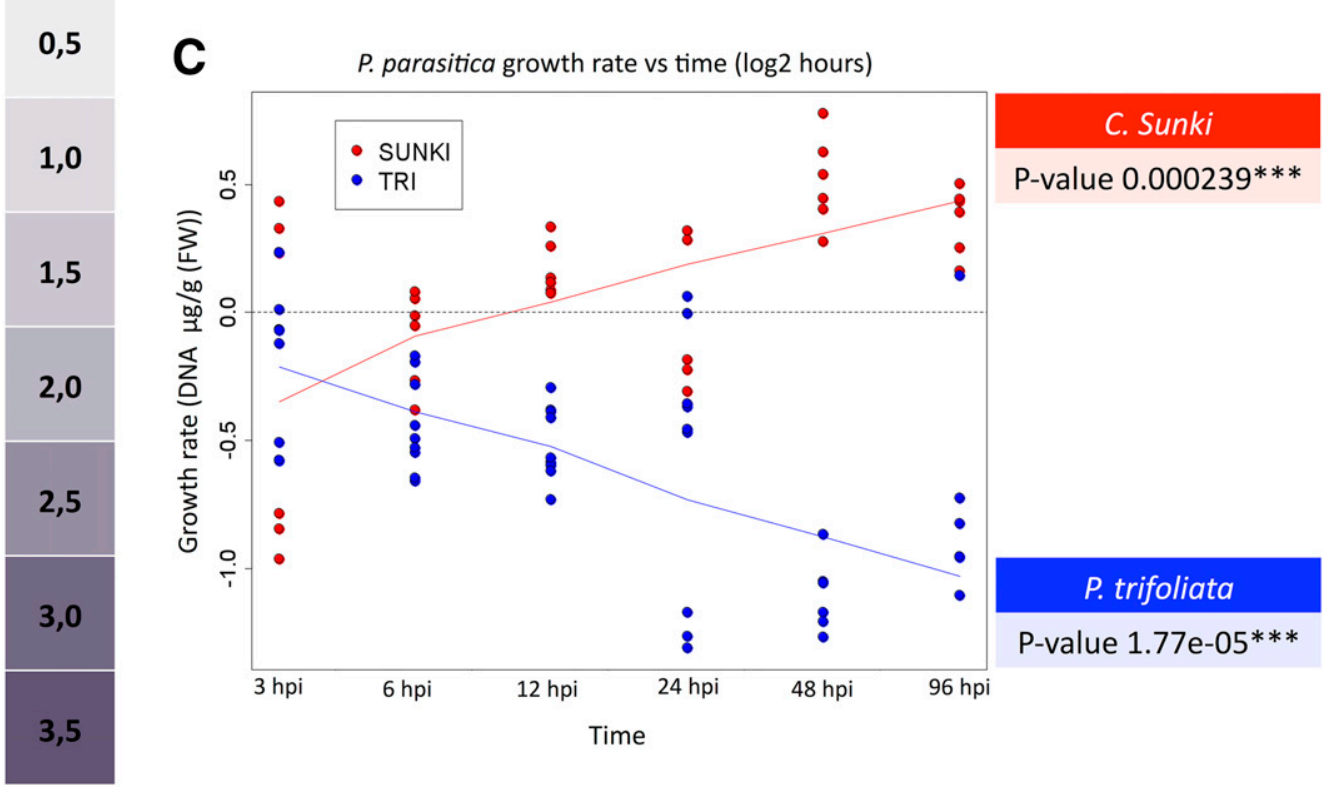

Fig. 3. A, Color scale of genomic DNA content. B, Phytophthora parasitica genomic DNA content in Citrus sunki and Poncirus trifoliata roots. C, Linear regression of the logarithm base 2 of the amount of P. parasitica genomic DNA (in micrograms per gram of fresh weight [FW]) in C. sunki and Poncirus trifoliata roots sampled at 3, 6, 12, 24, 48, and 96 hpi. Notice the increasing growth rate in C. sunki plants and a steadily decreasing rate in Poncirus trifoliata. Both relationships are highly statistically significant according to $P$ values.

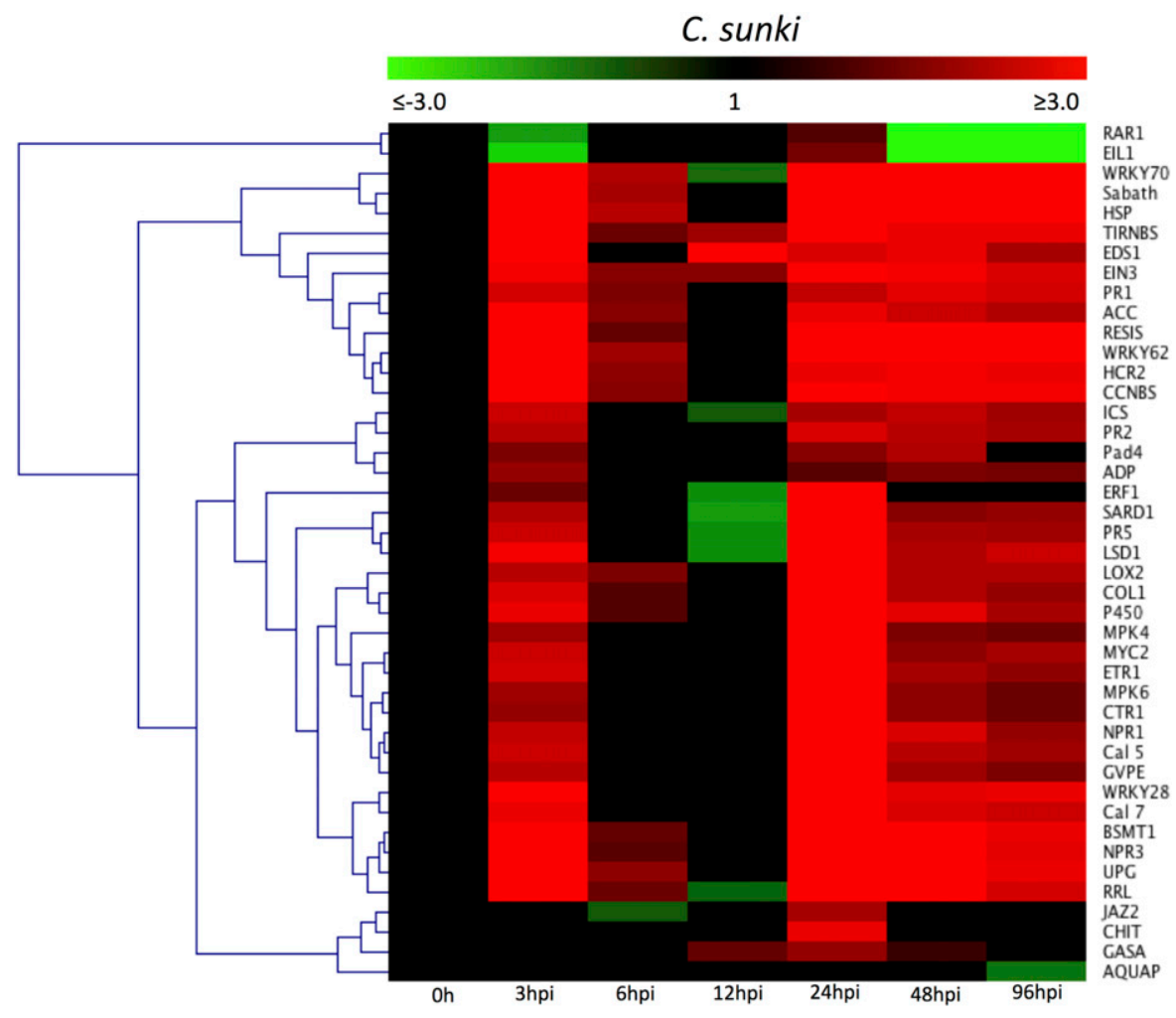

Fig. 4. Hierarchical clustering of gene expression in Phytophthora parasitica-infected Citrus sunki plants. The heat map illustrates the fold changes in gene expression ( $\log _{2}$ scale) in samples collected at $0,3,6,12,48$, and $96 \mathrm{~h}$ postinoculation (hpi). Different shades represent induced or repressed gene expression. Biological and technical triplicates were used in the analysis. Gene acronyms are listed in the column at the right. 
and 24 hpi (Fig. 9). Apart from PpCRN4, PpCRN8, and PpELI3, the other candidate effector genes were highly up-regulated at the later timepoints, when the infection was already established. Differently, in Poncirus trifoliata, the vast majority of $P$. parasitica effector genes, with the exception of PpELI3, were substantially induced at most of the timepoints, suggesting that $P$. parasitica actively secreted these effectors early in the infection, either as an attempt to break Poncirus trifoliata defense barriers or to manipulate the plant immune system (Fig. 10).

\section{DISCUSSION}

Deciphering the molecular mechanisms of pathogen effector deployment to favor infection in parallel with plant counterdefense strategies to avoid disease is a major focus of the plantmicrobe interaction research community. Frequently, plants can rapidly activate their defense system upon recognition of PAMPs or effectors and overcome disease development; however, this is not a rule. In the present study, we analyzed two citrus species with contrasting responses to $P$. parasitica infection (C. sunki, highly susceptible, and Poncirus trifoliata, resistant) and how their physiology is modulated under the influence of pathogen invasion and effector induction. Surprisingly, we found that the susceptible plant (C. sunki) rapidly recognizes $P$. parasitica invasion and strongly activates several genes related to SA, JA, and ET defense signaling pathways. Although robust, this defense boost was not sufficient to cope with $P$. parasitica invasion and prevent development of disease symptoms. On the other hand, Poncirus trifoliata did not show activation of any defense signaling pathway, although this citrus plant remains resistant to $P$. parasitica colonization, without development of disease symptoms.

A repertoire of genes related to defense response was therefore evaluated in susceptible and resistant citrus plants upon $P$. parasitica infection. Overall, most of the genes were induced in $C$. sunki, whereas only a few genes were differentially expressed in Poncirus trifoliata. We noticed that $C$. sunki responds with two tiers of defense against $P$. parasitica. First, a slight induction of defense genes early, at $3 \mathrm{hpi}$, is observed, followed by a basal gene expression at one or both 6 and $12 \mathrm{hpi}$, and second, a strong upregulation of these genes later, at 24 hpi. We have speculated that the first tier of defense might be mainly induced by general PAMPs, just after initial contact between plant and pathogen. Generally, a large number of defense-related genes are up-regulated following the perception of PAMPs by the PRRs present in the plant cell membranes (Li et al. 2016). Early-induced genes include those mainly related to the SA signaling pathway and defense responses (Lewis et al. 2015). This is consistent with the gene expression pattern observed in Figures 4 and 5.

Most of the evaluated genes related to the SA signaling pathway were up-regulated upon $P$. parasitica infection, except the $R A R 1$ gene, which was negatively regulated (Fig. 6). RARl is a component required for induction of the coiled coilnucleotide binding site (NBS) type resistance genes and further signaling responses (Song et al. 2013). The knockout rarl mutants are associated with limited ROS-induced programmed cell death (PCD) and with compromised basal resistance against fungi and bacteria pathogens. In this case, suppression of $R A R I$ might contribute to diminished ROS production and its effect on the pathogen colonization (Kaurilind et al. 2015). Furthermore, rarl mutants exhibit lower accumulation of immune receptors than wild-type plants (Bieri et al. 2004). HSP90, otherwise, was the most up-regulated gene in our analyses; HSP90 encodes a highly conserved and widely distributed chaperone, which, among other activities, mediates a signal transduction pathway that is linked to disease in plants (Xu et al. 2012). The complex formed by the interaction among HSP90, RAR1, and SUPPRESSOR OF THE G2 ALLELE OF SKP1 (SGT1) modulates the activation and stability of $\mathrm{R}$ proteins and contributes to the recognition of

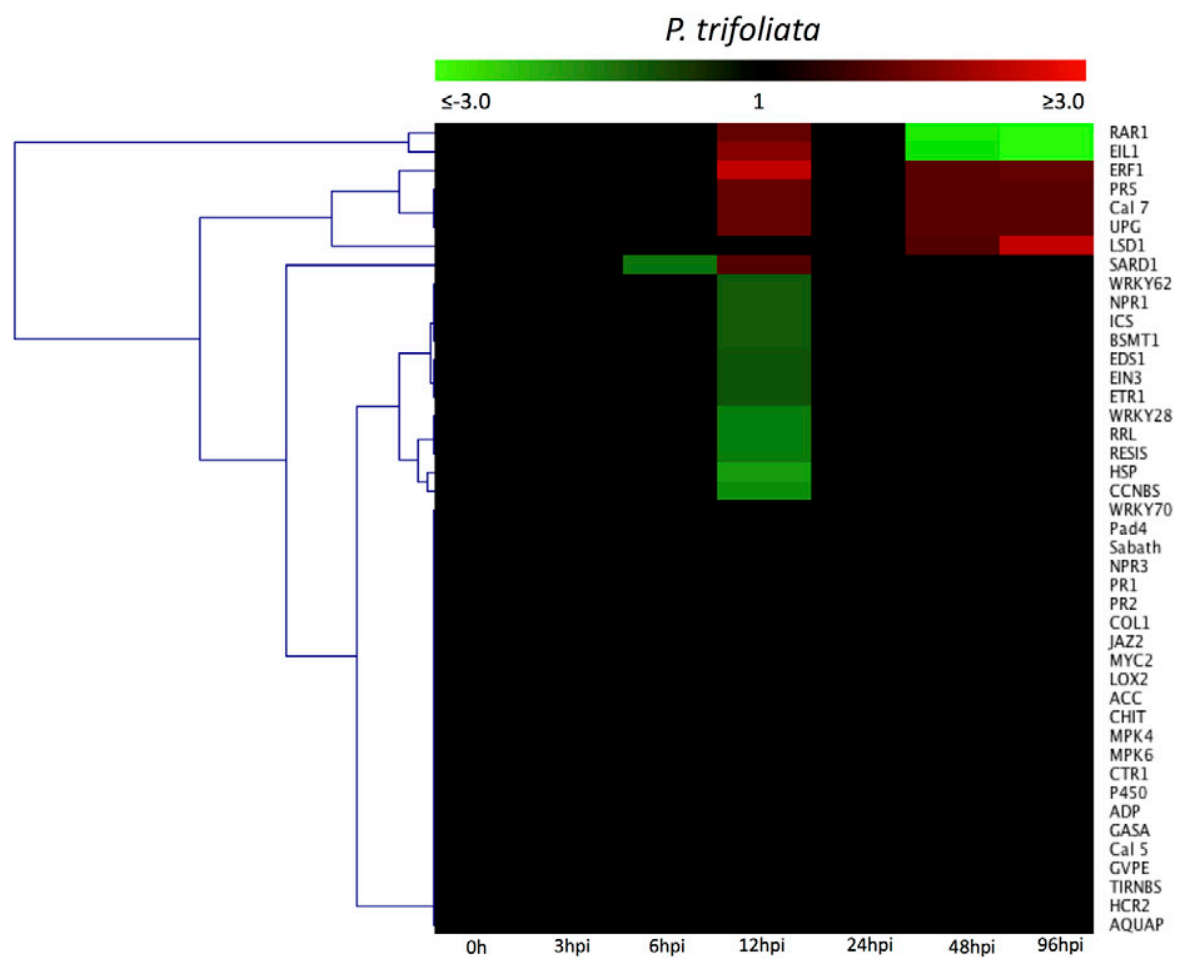

Fig. 5. Hierarchical clustering of gene expression in Phytophthora parasitica-infected Poncirus trifoliata plants. The heat map illustrates the fold changes in gene expression ( $\log _{2}$ scale) in samples collected at $0,3,6,12,48$, and $96 \mathrm{~h}$ postinoculation (hpi). Different shades represent induced or repressed gene expression. Biological and technical triplicates were used in the analysis. Gene acronyms are listed in the column at the right. 

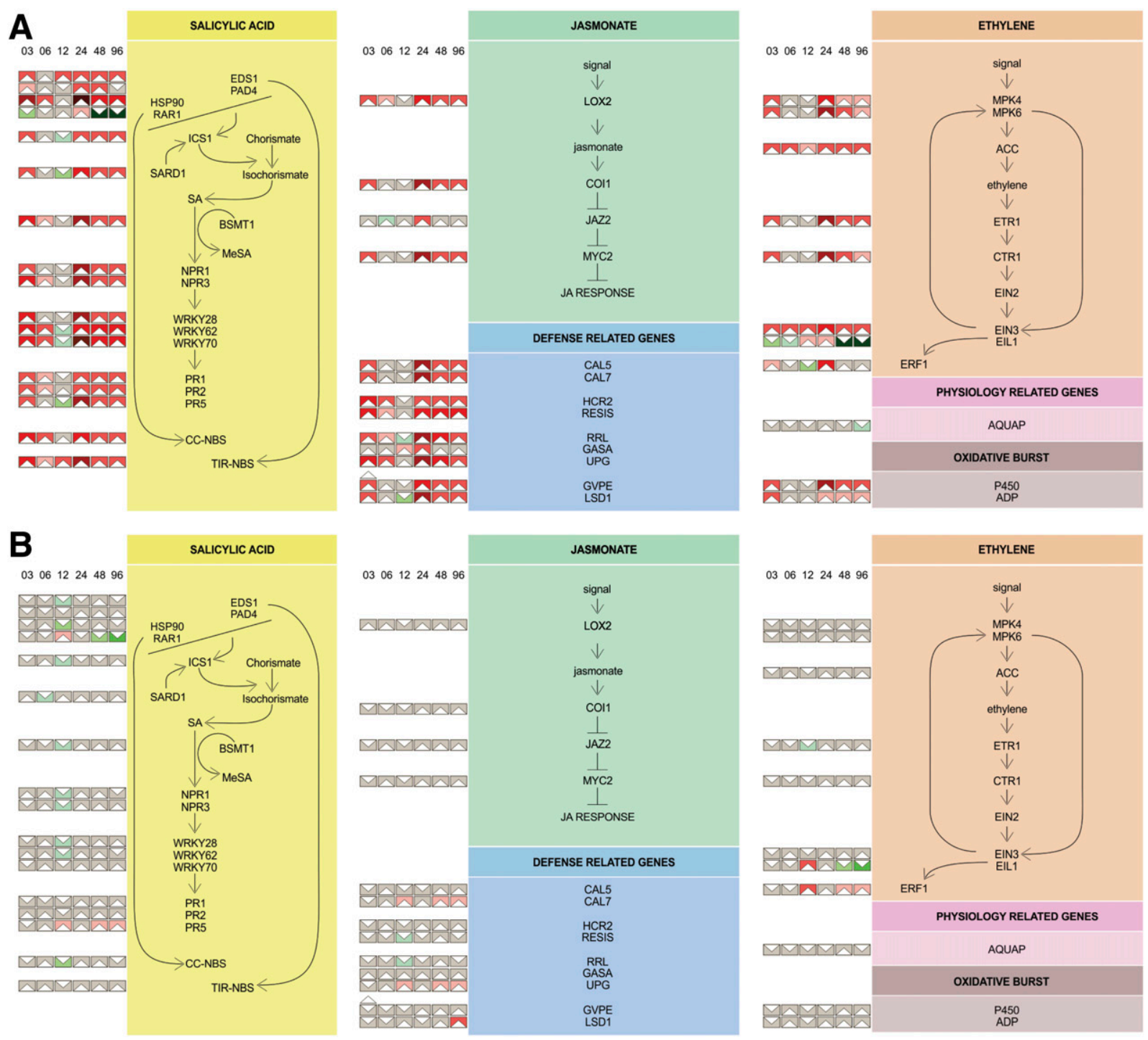

Fig. 6. Gene regulatory network of defense-related genes. A, Citrus sunki and B, Poncirus trifoliata plants upon Phytophthora parasitica infection. Genes were grouped into salicylic acid (SA), jasmonate, and ethylene pathways and oxidative burst-, defense-, and physiology-related genes. Different shades represent induced or repressed gene expression. Notice upregulation for most of the genes in $C$. sunki, in particular, SA-related genes, and a fair constitutive gene expression in Poncirus trifoliata.
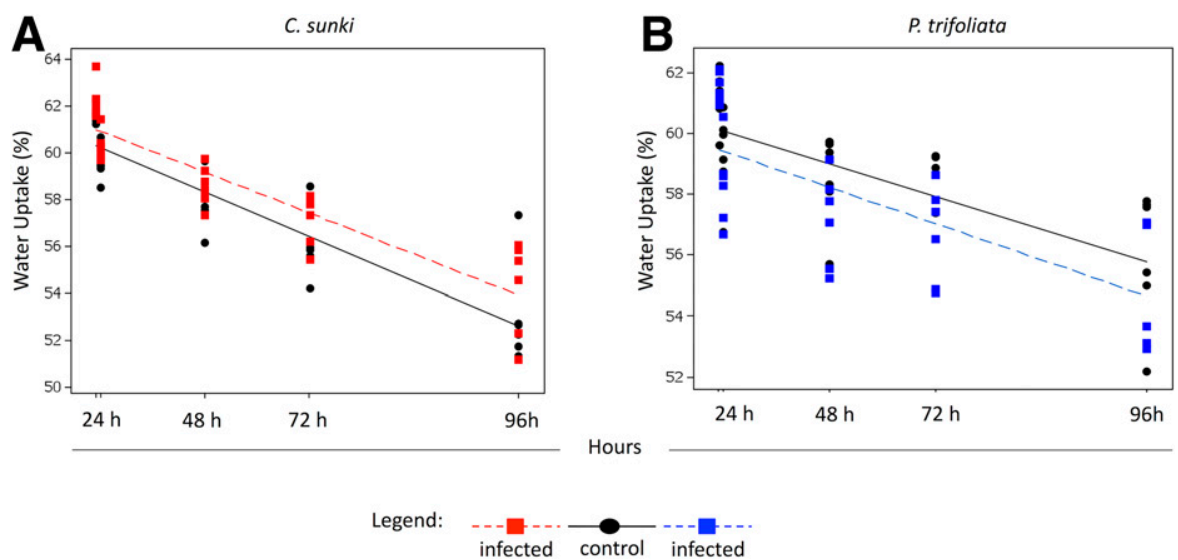

Fig. 7. Linear regression showing water uptake rate in Phytophthora parasitica-infected Citrus sunki and Poncirus trifoliata sampled at 24, 48, 72 , and $96 \mathrm{~h}$ postinoculation. A, Water uptake is higher in infected C. sunki compared with noninfected control plants, showing a statistically significant average difference of $0.91 \%$ (adjusted $P$ value, 0.0049). B, Poncirus trifoliata has an inverse behavior presenting a statistically significant average difference of $-0.80 \%$ (adjusted $P$ value, 0.0467379$)$. In both plants, the water uptake decreases in a linear pattern over time. 
pathogen effectors (Ito et al. 2015). On the other upstream branch of the SA pathway, ENHANCED DISEASE SUSCEPTIBILITY 1 (EDS1) and PHYTOALEXIN DEFICIENT 4 (PAD4) exhibited a steady-state expression over the course of the infection. These genes function along with SENESCENCE-ASSOCIATED GENE 101 (SAG101) as a complex that is required for regulating the expression of toll interleukin 1 receptor-NBS type resistance genes (Wagner et al. 2013).
A

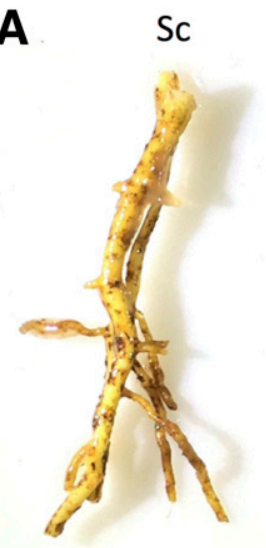

Si

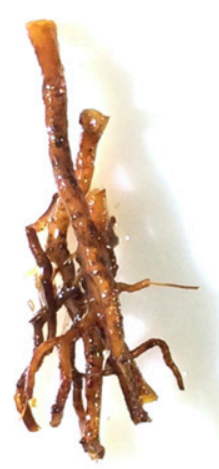

B
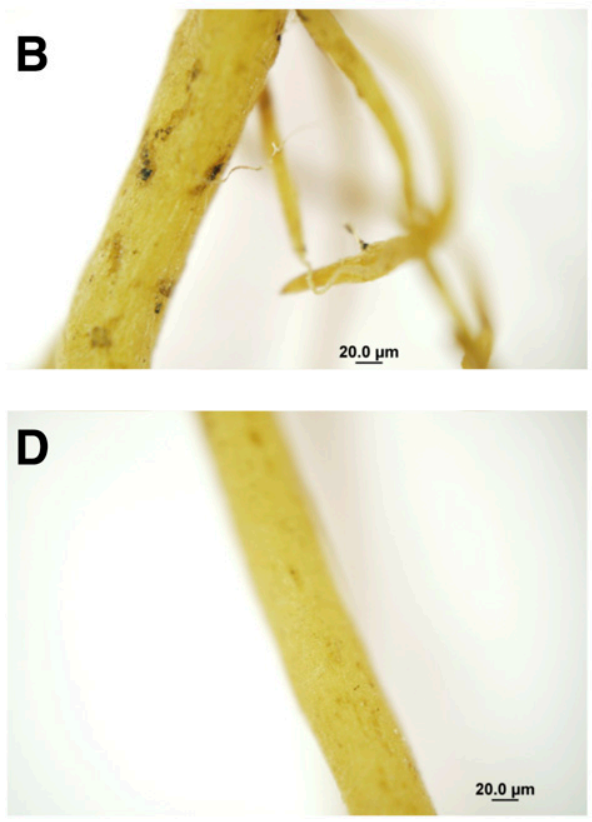

$\mathrm{Ti}$
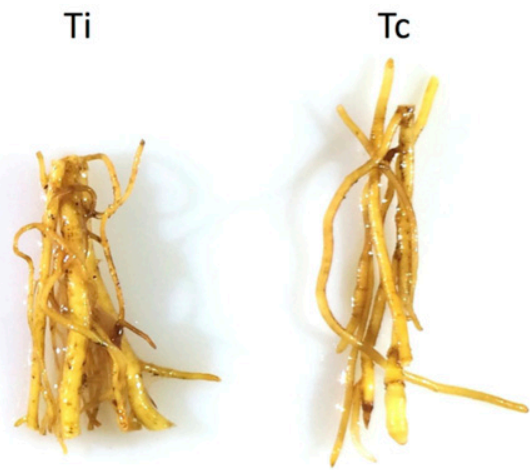

$1 \mathrm{~cm}$
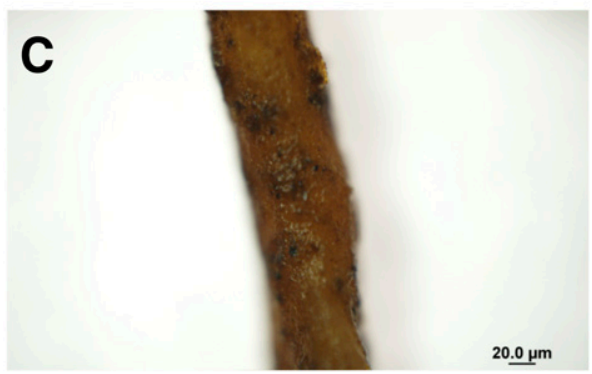

E

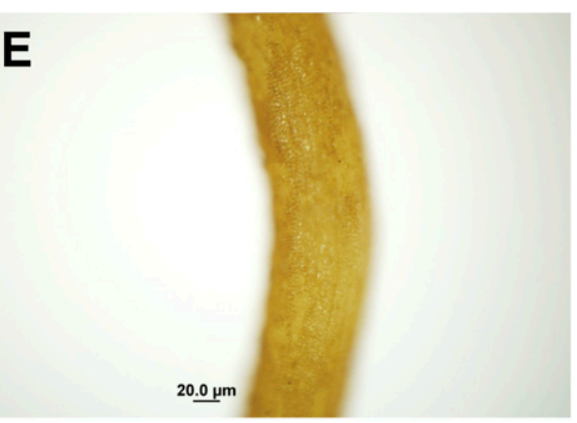

Fig. 8. A, Hydrogen peroxide $\left(\mathrm{H}_{2} \mathrm{O}_{2}\right)$ detection by diaminobenzidine tetrahydrochloride staining in Citrus sunki and Poncirus trifoliata roots infected with Phytophthora parasitica and sampled at $96 \mathrm{~h}$ postinoculation. B and Magnified view of root tips of $\mathbf{B}$, a control sample, C, P. parasitica-inoculated C. sunki, D, a control sample, and E, Poncirus trifoliata. $\mathrm{Sc}=$ C. sunki control, $\mathrm{Si}=$ C. sunki-inoculated, $\mathrm{Tc}=$ Poncirus trifoliata control, and $\mathrm{Ti}=$ Poncirus trifoliata-inoculated.

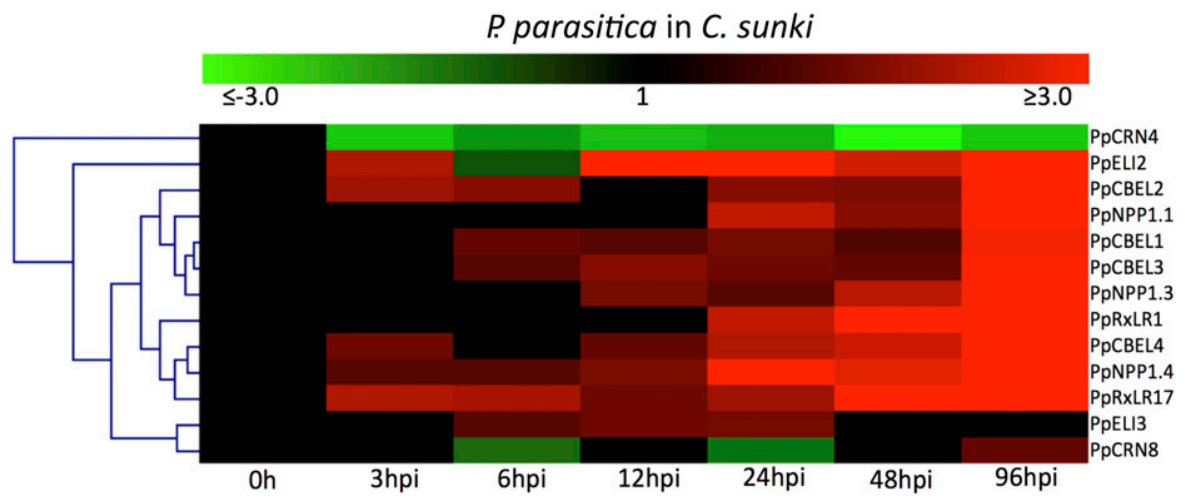

Fig. 9. Hierarchical clustering of gene expression of Phytophthora parasitica effectors during interaction with Citrus sunki at 0, 3, 6, 12, 24, 48, and 96 h postinoculation (hpi). The heat map illustrates fold change in expression $\left(\log _{2}\right.$ scale). Different shades represent induced or repressed gene expression. Apoplastic effectors (PpNPP1.1, PpNPP1.3, PpNPP1.4, PpELI2, PpELI3, PpCBEL1, PpCBEL2, PpCBEL3, PpCBEL4) and cytoplasmic effectors (PpRxLR1, PpRxLR17, PpCRN4, PpCRN8) were evaluated. 
Genes related to SA biosynthesis and metabolism, such as ISOCHORISMATE SYNTHASE 1 (ICS1), SAR DEFICIENT 1 (SARD1), BENZOIC ACID/SALICYLIC ACID CARBOXYL METHYLTRANSFERASE 1 (BSMT1), and SA CARBOXYL METHYLTRANSFERASE (SABATH), had a similar gene expression profile, with a slight upregulation at 3 and 24 hpi (Fig. 6). Among them, BSMT1 and SABATH were the most-induced genes, and both encode for methyltransferase proteins with activity over SA (Hippauf et al. 2010). The derivative methyl salicylate, produced by methyltranferase activity, can be transported to distal tissues through the phloem and it activates a systemic defense response, after being converted into SA by enzymes, such as SABATH, and triggering downstream SA signaling ( $\mathrm{Fu}$ and Dong 2013). Therefore, a defense response associated to SAR might be active in $C$. sunki upon $P$. parasitica infection.

Altogether, the defense-related genes that act downstream in the SA signaling pathway, which includes transcription factors, pathogenesis-related proteins, and NBS genes, showed as upregulated during infection (Fig. 6). This indicates that $P$. parasitica induces general defense mechanisms mediated by SA; however, this phytohormone signaling pathway is not sufficient to promote C. sunki resistance.

Furthermore, we also evaluated key genes related to JA and ET signaling pathways, as these phytohormones, in conjunction with SA, act in a crosstalk network that regulates plant defenses. A similar expression profile of JA- and SA-related genes was observed. Additionally, a consistent regulation of CORONATINE INSENSITIVE 1 (COII) expression, which negatively regulates JASMONATE-ZIM-DOMAIN PROTEIN 2 (JAZ2) and consequently induces $M Y C 2$ expression (Turner et al. 2002), was here observed. MYC2 modulates a range of JA-dependent functions, including the regulation of defense mechanisms against pathogens and herbivores (Dombrecht et al. 2007). For ET-related gene expression, we detected an upregulation of most genes that are upstream in this signaling pathway. However, the gene ETHYLENEINSENSITIVE3-LIKE 1 (EIL1), which encodes a transcription factor, was repressed during infection. EIL1 coordinates several ET responses, including plant development and defense responses (An et al. 2010).

We also evaluated genes that are associated with general defense responses, for instance, Callose Synthase, GAMMA VACUOLAR PROCESSING ENZYME (GVPE), LESION SIMULATING DISEASE 1 ( $L S D 1)$. All these genes were induced, following the same profile of two waves of upregulation. GPVE is a vacuolar processing enzyme that is up-regulated under stress conditions and is associated to cell death (Qiang et al. 2012). LSD1 regulates cell death by interacting with catalases that control the level of ROS into cells (Coll et al. 2011). These findings confirm that $C$. sunki plants activate general defense mechanisms upon infection; however, these mechanisms do not contribute to plant resistance.

In contrast, Poncirus trifoliata defense-gene transcripts were weakly detected upon $P$. parasitica infection. We have speculated that the pathogen may not be adapted to surpass preformed physical and biochemical barriers and, thus, may be unable to penetrate and colonize this plant tissues; no symptoms or alteration in gene expression of the major defense signaling pathways were observed. Boava and coworkers (2011) reported the induction of defense-related genes in Poncirus trifoliata after $P$. parasitica inoculation and observed the development of small lesions induced by the pathogen. However, the pathogen inoculation by wounding method was used in this experiment (Boava et al. 2011), which should have favored the initial pathogen colonization and triggered a defense response, further impairing disease progression. We assume this proposition because, in natural environmental conditions, $P$. parasitica is unable to surpass structural or chemical barriers to establish an effective colonization. The inoculation method via zoospores herein performed might be a closer mimic to natural interacting conditions and, additionally, no mechanical or wound lesions were supplement to $P$. parasitica inoculation.

The $P$. parasitica-citrus pathosystem represents a hemibiotrophic plant-pathogen interaction. We demonstrated that SA, $\mathrm{JA}$, and ET signaling pathways were activated in $C$. sunki upon infection. Attard et al. (2010) found similar results in A. thaliana plants and suggested that these phytohormone pathways cooperate for defense during root infection. We observed that the gene expression levels in $C$. sunki culminated in HR, which is a type of PCD. The HR was confirmed by histochemistry with detection of high levels of peroxidase activity in $C$. sunki-infected tissues (Fig. 7). ROS generation, especially $\mathrm{H}_{2} \mathrm{O}_{2}$, have been reported as the first plant-cell response against pathogen attack (Mellersh et al. 2002; Shetty et al. 2003; Thordal-Christensen et al. 1997). During stress conditions, plant cells are able to induce the so-called oxidative burst consisting mainly of $\mathrm{H}_{2} \mathrm{O}_{2}$ production. This ROS accumulation plays a central role during HR, triggering defense responses. HR has been reported in different plant species, in response to interaction with bacteria, fungi, viruses, oomycetes, nematodes, insects, and parasitic plants (Govrin and Levine 2000; Höglund et al. 2005; Huang et al. 2010; Runyon et al. 2010; Vleeshouwers et al. 2000; Wang and Wang 2016). Our analysis of $\mathrm{H}_{2} \mathrm{O}_{2}$ accumulation by DAB supports the occurrence of HR in C. sunki, but this defense strategy was not sufficient to impair the pathogen colonization. The hemibiotrophic lifestyle of $P$. parasitica allows feeding on dead tissue, and therefore, the HR mechanism employed by $C$. sunki is not efficient, since cell death is induced, which favors the exponential growth of $P$. parasitica in

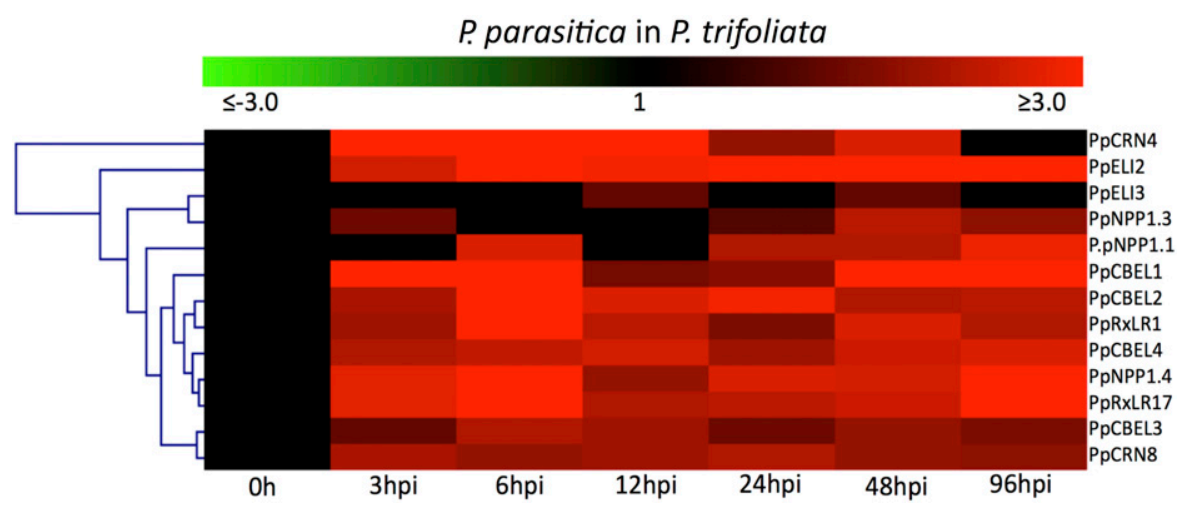

Fig. 10. Hierarchical clustering of expression of Phytophthora parasitica effector genes in interaction with Poncirus trifoliata at 0 , 3, 6, 12, 24, 48, and 96 h postinoculation (hpi). The heat map illustrates fold change in expression $\left(\log _{2}\right.$ scale). Different shades represent induced or repressed gene expression. Apoplastic effectors (PpNPP1.1, PpNPP1.3, PpNPP1.4, PpELI2, PpELI3, PpCBEL1, PpCBEL2, PpCBEL3, PpCBEL4) and cytoplasmic effectors (PpRxLR1, PpRxLR17, PpCRN4, PpCRN8) were evaluated. 
infected root tissues (Figs. 2 and 3). On the other hand, a HR response in Poncirus trifoliata plants was not observed (Fig. 8), indicating that Poncirus trifoliata resistance is not via HR and is likely to be driven by preformed physical and biochemical barriers found in this citrus species.

The reactions observed in both plant hosts upon infection seem to be an all-or-none response, in which the SA, JA, and ET signaling pathways were insufficient to restrain the development of the pathogen in $C$. sunki plants, while no genetic reprogramming related to these phytohormones was observed in Poncirus trifoliata. Additionally, we could not detect any indication of pathogen development in Poncirus trifoliata, which suggests that Poncirus trifoliata is a nonhost plant species to $P$. parasitica. Several studies have reported that haustoria development fails in nonhost plants (Bettgenhaeuser et al. 2014; Cheng et al. 2012; Ellis 2006). Furthermore, nonhost resistance in Poncirus trifoliata might be associated with multiple quantitative trait loci (QTL), as indicated by studies with filamentous pathogens, assuming that the pathogen can secrete distinct effector proteins (Stam et al. 2014).

In $C$. sunki, the candidate effector genes PpELI2, PpELI3, PpNPP1.4, PpCBEL2, PpCBEL4, and PpRxLR17 showed upregulation at the beginning of the infection (3, 6, and $12 \mathrm{hpi})$ (Fig. 9). Elicitins and NPP1 are associated with induction of necrosis (Du et al. 2015; Fellbrich et al. 2002). CBEL genes are associated with pathogen adhesion in plant cell surfaces (Gaulin et al. 2002). RxLR genes are associated with either defense suppression or activation via manipulation of hormonal pathways (Anderson et al. 2015). Although a functional characterization of these genes is required, the putative secretion of these effectors at the beginning of infection might suggest an induction of necrosis, rapid adhesion and colonization, and hormone signaling disturbance. Altogether, these events would explain the disease progression triggered by $P$. parasitica in $C$. sunki plants.

In Poncirus trifoliata, all putative pathogenic effectors had their expression strongly upregulated at the early timepoints
(Fig. 10); nevertheless, this had no effect in transcriptional changes of defense-related genes and other physiological genes. The overall increase of gene transcription that encodes putative effectors, suggests an increasing attempt of $P$. parasitica to break Poncirus trifoliata barriers and establish an infective process. Particularly at $6 \mathrm{hpi}$, genes such as CBEL, ELI, RxLR, and $C R N$ were strongly expressed, without induction of tissue necrosis, pathogen colonization, or host immunity manipulation, singly or in combination. It is plausible that Poncirus trifoliata seedlings lack one or more molecular targets of those effectors or that it is not necessary for this resistant plant to activate defenses, since there is basically no penetration of hyphae.

The main events recorded for $P$. parasitica interaction along with $C$. sunki and Poncirus trifoliata seedlings is summarized in Figure 11. In $C$. sunki plants, this pathogenic oomycete invades root tissues and deploys several molecular effectors already at early stages of infection. The susceptible plant responds to pathogen attack by a strong activation of genes related to the main defense signaling pathways, i.e., SA, JA, and ET, and this major transcriptional reprogram results in HR. However, this is not efficient to kill or prevent pathogen colonization. Because $P$. parasitica has a hemibiotrophic lifestyle, it might benefit from cell death triggered by HR and release of nutrients from the plant. In Poncirus trifoliata, otherwise, despite contact with several $P$. parasitica effectors, activation of SA, JA, or ET signaling pathways is not detected. The only physiological shift triggered by $P$. parasitica in this resistant plant was a decrease in water consumption, which indicates that the main defense strategy employed by Poncirus trifoliata is its preformed biochemical or anatomical barriers, or both. Future works should take advantage of these data to generate efficient control strategies or resistant plants, based on i) conventional breeding programs, via use of QTL or expressed QTL to generate citrandarins and ii) biotechnology-based approaches, which include the development of transgenic or cisgenic citrus, genome editing, and host-induced gene silencing (HIGS).
A

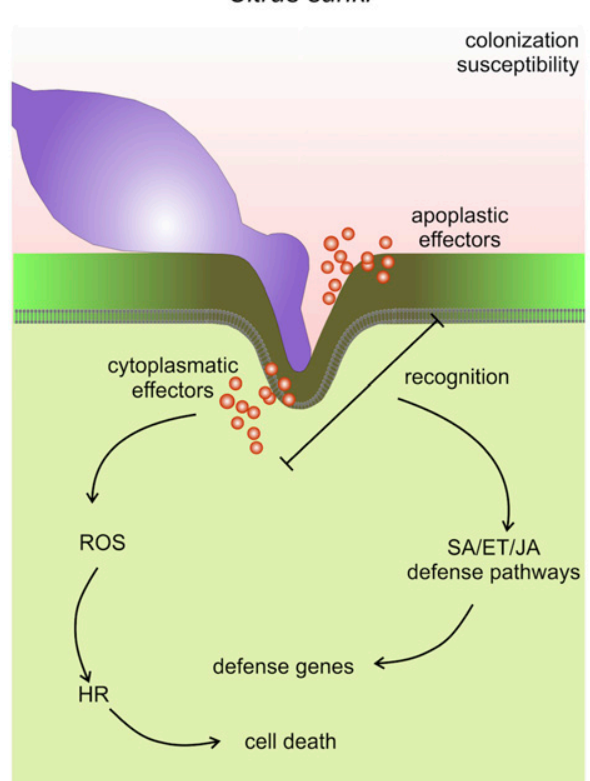

B

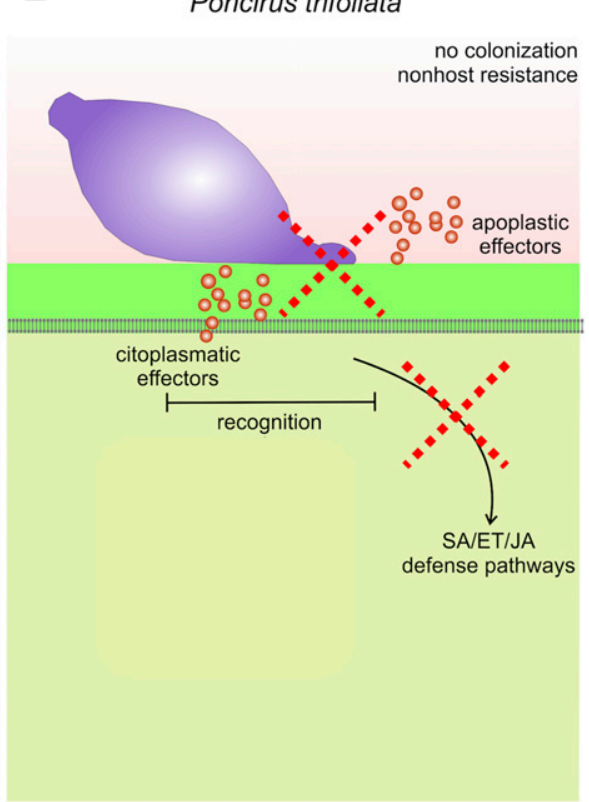

Fig. 11. Model of the interaction between Phytophthora parasitica and citrus plants. A, In Citrus sunki, P. parasitica colonizes root tissues and triggers the expression of several defense-related genes. High reactive oxygen species production and necrosis are observed. Cell death might not be effective as defense strategy against this hemibiotrophic pathogen and may, instead, favor pathogen development. B, In Poncirus trifoliata, P. parasitica colonization is not observed. In this interaction, most defense-related genes had a constitutive expression throughout infection. Expression of apoplastic and cytoplasmic effectors, which may suppress the defense response, is detected. These results indicate that Poncirus trifoliata may recognize the pathogen, but its resistance relies mainly on preformed biochemical and anatomical barriers. 


\section{MATERIALS AND METHODS}

\section{Oomycete growth conditions.}

Phytophthora parasitica (isolate IAC_01/95.1) was grown in a carrot-agar medium, at $25^{\circ} \mathrm{C}$ in the dark. Sporangia development was performed according to Dalio et al. (2014). Briefly, after the colony reaching up to $80 \%$ of the plate capacity, sporangia development was induced by pouring sterile water on the plate and replacing water daily for 1 week. To induce release of zoospores, plates were incubated at $4^{\circ} \mathrm{C}$, in the dark, for $1 \mathrm{~h}$. Zoospore suspension was collected and was adjusted to a concentration of $10^{5}$ zoospores per milliliter. The number of zoospores in suspension was recorded using a Neubauer chamber.

\section{Plant growth conditions and $\boldsymbol{P}$. parasitica infection assay.}

Seeds of $C$. sunki and Poncirus trifoliata were germinated in sterile substrate. After 3 months, substrate was carefully removed and plants were transferred to a tube containing $50 \mathrm{ml}$ of sterile distilled water. Zoospore suspension was added to the tube, which was next sealed with parafilm, to avoid water loss to evaporation. Plants were incubated in growth chambers at $20^{\circ} \mathrm{C}$, under a $12 \mathrm{~h}$ photoperiod $\left(250 \mu \mathrm{mol} \mathrm{m} \mathrm{m}^{-2} \mathrm{~s}^{-1}\right.$ photosynthetic photon flux density). Six biological replicates were used in each treatment and the infection assay was performed in two independent replicates. Daily, plants were monitored for root necrosis, growth of visible mycelia on root surface, wilting leaves, mortality, and water uptake. Plants were also harvested at $0,3,6,12,24,48$, and 96 hpi and were used to measure $P$. parasitica genomic DNA content and tissue (roots and leaves) damage and for expression analysis of genes from citrus plants and $P$. parasitica.

\section{Microscopy analysis.}

Root tips were sampled 96 hpi and were fixed in Karnovsky solution (2\% paraformaldehyde, $2.5 \%$ glutaraldehyde, and $0.1 \mathrm{M}$ phosphate buffer) for 3 days. Subsequently, they were washed in phosphate buffer, were embedded in paraffin, and were sectioned longitudinally. Each $1 \mu \mathrm{m}$ section was transferred to slides, stained with $0.05 \%$ toluidine blue for $8 \mathrm{~min}$, was analyzed under light microscope, and was photo documented.

\section{ROS measurement in $\boldsymbol{P}$. parasitica-infected plants.}

To detect ROS generation (specifically $\mathrm{H}_{2} \mathrm{O}_{2}$ production) in roots of $C$. sunki and Poncirus trifoliata seedlings (24-hpi infected and noninfected plants), we performed a DAB assay according to Thordal-Christensen et al. (1997) and Salzer et al. (1999). Briefly, DAB polymerizes when in contact with $\mathrm{H}_{2} \mathrm{O}_{2}$ and the peroxidase enzyme, resulting locally in a brownish to black color in the tissues. Stained root samples were subsequently analyzed under a stereoscope light microscopy.

\section{Isolation and quantification of $\boldsymbol{P}$. parasitica genomic DNA.}

First, $100 \mathrm{mg}$ of fresh mycelia were ground in liquid nitrogen and the resulting powder was transferred to a $1.5-\mathrm{ml}$ sterile tube. Genomic DNA isolation was then performed using DNeasy plant mini kit (Qiagen, Hilden, Germany), and further purification was performed using the Wizard DNA clean up system (Promega, Mannheim, Germany), according to manufacturer's recommendations. DNA quality and purity were checked on Nanodrop (NanoDrop 8000, Thermo Fisher Scientific, Waltham, MA, U.S.A.).

To quantify $P$. parasitica DNA content, reverse transcription RT-qPCR analyses was performed targeting the PN5b-PN6 genes. DNA was diluted in $\mathrm{H}_{2} \mathrm{O}(1: 10)$ to prevent PCR inhibition. RT-qPCR were performed in Applied Biosystems 7500 Real-Time PCR System using GoTaq Real-Time qPCR (Promega), according to manufacturer's recommendations. Briefly, each $20-\mu$ l reaction contained $1 \mu \mathrm{l}$ of DNA template, $1.1 \mu \mathrm{l}$ of $\mathrm{H}_{2} \mathrm{O}$,
$10 \mu \mathrm{l}$ of Go-Taq qPCR Master mix, and $0.25 \mu \mathrm{l}$ of $10-\mathrm{pmol} / \mu \mathrm{l}$ primer solution. Primers were $\beta$-actin PN5b (5' GAACAATG CAACTTATTGGACGTT 3') and PN6 (5' AACCGAAGCTGCC ACCCTAC $3^{\prime}$ ), generating an amplicon with a fragment size of $120 \mathrm{bp}$ (Ippolito et al. 2002). Amplification conditions were $95^{\circ} \mathrm{C}$ for $10 \mathrm{~min}$ and 40 cycles of $95^{\circ} \mathrm{C}$ for $15 \mathrm{~s}, 62^{\circ} \mathrm{C}$ for $60 \mathrm{~s}$. Melt curve analysis was performed by raising the temperature from 65 to $95^{\circ} \mathrm{C}$, in $0.5^{\circ} \mathrm{C}$ steps for $5 \mathrm{~s}$ each, to detect specificity by dissociation of amplicons and primer dimers formation. Reactions were performed in three biological and technical replicates. Cycle threshold values of samples were compared with a standard curve (obtained using genomic DNA isolated from $P$. parasitica grown in petri plates with carrot medium) to determine the concentration of each sample. The standard curve concentrations ranged from $1 \mathrm{pg}$ of DNA ml$l^{-1}$ to $10 \mathrm{ng}$ of DNA ml $\mathrm{m}^{-1}$ in five steps.

\section{Gene expression analysis.}

For $C$. sunki and Poncirus trifoliata gene-expression analysis, we selected genes related to defense pathways, including SA, ET, and JA, normal physiological conditions, and other general defense-related genes. Arabidopsis thaliana gene sequences were obtained from The Arabidopsis Information Resource (TAIR) and were used for a blast search of citrus orthologous genes by BLASTX on Phytozome, selecting the sequence with the highest hit score, based on identity and query cover, i.e., lowest E-value. Primers were designed using Primer3 Plus software, considering the following parameters: 40 to $60 \%$ GC content, 18 to $24 \mathrm{nt}$ primer length, annealing temperature of $60^{\circ} \mathrm{C} \pm 2$, and 70 to $200 \mathrm{bp}$ amplicon length. Total RNA was extracted from $50 \mathrm{mg}$ of root tissue, using MasterPure plant RNA purification kit (Epicentre Biotechnologies, Madison, WI, U.S.A.), followed by DNaseI (Thermo Fisher Scientific) treatment, according to manufacturer's recommendations.

For $P$. parasitica analysis, we developed a bioinformatic pipeline for the prediction of candidate secreted effector proteins, considering the following parameters: presence of signal peptides, predicted by Signalp v.3.0 software (Bendtsen et al. 2004); absence of transmembrane helices and glycosylphosphatidylinositol (GPI) anchors, predicted, respectively, by TMHMM software (Krogh et al. 2001) and GPIsom software (Fankhauser and Mäser 2005). Based on predictions, candidate effectors were retrieved from 22,113 evaluated sequences. Among the predicted sequences, we selected sequences of apoplastic and cytoplasmic effectors (RxLR and CRN effectors) and sequences with predicted domains of known elicitors, such as NPP1 and CBEL. RT-qPCR primers were designed using Primer3 Plus following the same parameters set for citrus, described previously.

Total mRNAs (from C. sunki, Poncirus trifoliata, and $P$. parasitica) were reverse transcribed using oligo-dT primers in a $20-\mu 1$ reaction volume, using RevertAid first-strand cDNA synthesis kit (Thermo Fisher Scientific) and $1 \mu \mathrm{g}$ of total DNAfree RNA. cDNA was diluted (1:20), and $1 \mu \mathrm{l}$ of the diluted cDNA was used in a $13-\mu \mathrm{l}$ volume reaction containing $6.75 \mu \mathrm{l}$ of Go-Taq qPCR Master mix and $0.75 \mu \mathrm{M}(1 \mu \mathrm{l})$ of each primer. RT-qPCR were performed in the Applied Biosystem 7500, in triplicate reactions with the following conditions: $95^{\circ} \mathrm{C}$ for $20 \mathrm{~s}$ and 40 cycles of $95^{\circ} \mathrm{C}$ for $3 \mathrm{~s}, 60^{\circ} \mathrm{C}$ for $30 \mathrm{~s}$. Melt curve analysis was performed by raising the temperature from 65 to $95^{\circ} \mathrm{C}$, in $0.5^{\circ} \mathrm{C}$ steps for $5 \mathrm{~s}$ each, to detect specificity by dissociation of amplicons and primer dimers formation. A list of primers and sequences used in this study can be found in Supplementary Table S1.

\section{Analysis of housekeeping reference genes.}

We tested several housekeeping genes for the normalization of gene expression in $P$. parasitica-infected plants. The 
stability of GAPC2 (glyceraldehyde-3-phosphate dehydrogenase C2), EGIDH (NADP-isocitrate dehydrogenase), DIM1 (DIM1 homolog/YLS8), CYP (cyclophilin), FBOX (FBOX family protein), GAPC2 (glyceraldehyde-3-phosphate dehydrogenase C2) was investigated using geNorm and NormFinder software programs. Sequences of these housekeeping genes were searched and retrieved from the databases CitEST and HarvEST.

\section{Statistical analysis.}

Differences between the amount of $P$. parasitica genomic DNA in C. sunki and Poncirus trifoliata roots were analyzed using a linear regression approach, presented in Figure 3. Lines reflect the logarithm base 2 of the amount of genomic DNA (micrograms of DNA per gram) per time course point $(3,6,12$, 24,48 , and $96 \mathrm{hpi}$ ) for both plants and the regression statistical significance is reflected in F-test $P$ value.

Water uptake rate, in $C$. sunki and Poncirus trifoliata, was evaluated at 24, 48, 72, and $96 \mathrm{hpi}$, using a linear regression model with time course and a dummy explanatory variable to identify control and infected plants.

For statistical analysis of gene expression, quantification cycle value $(\mathrm{Cq})$, and primer efficiency values were calculated from raw fluorescent data (Rn values), using the Real-time PCR Miner program (Zhao and Fernald 2005). Housekeeping genes used for normalization in citrus were $C Y P, F B O X I$, and $G A P C 2$, and, for $P$. parasitica, $U B C$ (ubiquitin $C$ ) and $S 3 A$ (ribosomal protein $\mathrm{S} 3 \mathrm{~A}$ ) genes. Relative quantification $(\mathrm{Rq})$ was calculated using $2^{-\Delta \Delta \mathrm{Cq}}$, and the significance of the results was tested using the Kruskal-Wallis test.

\section{LITERATURE CITED}

Ahuja, I., Kissen, R., and Bones, A. M. 2012. Phytoalexins in defense against pathogens. Trends Plant Sci. 17:73-90.

An, F., Zhao, Q., Ji, Y., Li, W., Jiang, Z., Yu, X., Zhang, C., Han, Y., He, W., Liu, Y., Zhang, S., Ecker, J. R., and Guo, H. 2010. Ethylene-induced stabilization of ETHYLENE INSENSITIVE3 and EIN3-LIKE1 is mediated by proteasomal degradation of EIN3 binding F-box 1 and 2 that requires EIN2 in Arabidopsis. Plant Cell 22:2384-2401.

Anderson, R. G., Deb, D., Fedkenheuer, K., and McDowell, J. M. 2015 Recent progress in RXLR effector research. Mol. Plant-Microbe Interact. 28: 1063-1072.

Attard, A., Evangelisti, E., Kebdani-Minet, N., Panabières, F., Deleury, E., Maggio, C., Ponchet, M., and Gourgues, M. 2014. Transcriptome dynamics of Arabidopsis thaliana root penetration by the oomycete pathogen Phytophthora parasitica. BMC Genomics 15:538.

Attard, A., Gourgues, M., Callemeyn-Torre, N., and Keller, H. 2010. The immediate activation of defense responses in Arabidopsis roots is not sufficient to prevent Phytophthora parasitica infection. New Phytol. 187:449-460.

Bendtsen, J. D., Nielsen, H., von Heijne, G., and Brunak, S. 2004. Improved prediction of signal peptides: SignalP 3.0. J. Mol. Biol. 340:783-795.

Bettgenhaeuser, J., Gilbert, B., Ayliffe, M., and Moscou, M. J. 2014. Nonhost resistance to rust pathogens-A continuation of continua. Front. Plant Sci. 5:664

Bieri, S., Mauch, S., Shen, Q. H., Peart, J., Devoto, A., Casais, C., Ceron, F., Schulze, S., Steinbiss, H. H., Shirasu, K., and Schulze-Lefert, P. 2004. RAR1 positively controls steady state levels of barley MLA resistance proteins and enables sufficient MLA6 accumulation for effective resistance. Plant Cell 16:3480-3495.

Bigeard, J., Colcombet, J., and Hirt, H. 2015. Signaling mechanisms in pattern-triggered immunity (PTI). Mol. Plant 8:521-539.

Boava, L. P., Cristofani-Yaly, M., Mafra, V. S., Kubo, K., Kishi, L. T., Takita, M. A., Ribeiro-Alves, M., and Machado, M. A. 2011. Global gene expression of Poncirus trifoliata, Citrus sunki and their hybrids under infection of Phytophthora parasitica. BMC Genomics 12:39.

Boyko, A., and Kovalchuk, I. 2011. Genetic and epigenetic effects of plantpathogen interactions: An evolutionary perspective. Mol. Plant 4:1014-1023.

Cheng, Y., Zhang, H., Yao, J., Wang, X., Xu, J., Han, Q., Wei, G., Huang, L., and Kang, Z. 2012. Characterization of non-host resistance in broad bean to the wheat stripe rust pathogen. BMC Plant Biol. 12:96.

Chisholm, S. T., Coaker, G., Day, B., and Staskawicz, B. J. 2006. Hostmicrobe interactions: Shaping the evolution of the plant immune response. Cell 124:803-814.
Coll, N. S., Epple, P., and Dangl, J. L. 2011. Programmed cell death in the plant immune system. Cell Death Differ. 18:1247-1256.

Cui, H., Tsuda, K., and Parker, J. E. 2015. Effector-triggered immunity: From pathogen perception to robust defense. Annu. Rev. Plant Biol. 66: 487-511.

Cuming, A. C. 2009. Plant-pathogen interactions: A view from the evolutionary basement. New Phytol. 183:237-239.

Dalio, R. J., Fleischmann, F., Humez, M., and Osswald, W. 2014. Phosphite protects Fagus sylvatica seedlings towards Phytophthora plurivora via local toxicity, priming and facilitation of pathogen recognition. PLoS One 9:e87860.

Dalio, R. J. D., Magalhães, D. M., Rodrigues, C. M., Arena, G. D., Oliveira, T. S., Souza-Neto, R. R., Picchi, S. C., Martins, P. M. M., Santos, P. J. C., Maximo, H. J., Pacheco, I. S., De Souza, A. A., and Machado, M. A. 2017. PAMPs, PRRs, effectors and R-genes associated with citrus-pathogen interactions. Ann. Bot. 119:749-774.

Dombrecht, B., Xue, G. P., Sprague, S. J., Kirkegaard, J. A., Ross, J. J., Reid, J. B., Fitt, G. P., Sewelam, N., Schenk, P. M., Manners, J. M., and Kazan, K. 2007. MYC2 differentially modulates diverse jasmonatedependent functions in Arabidopsis. Plant Cell 19:2225-2245.

Du, J., Verzaux, E., Chaparro-Garcia, A., Bijsterbosch, G., Keizer, L. C., Zhou, J., Liebrand, T. W., Xie, C., Govers, F., Robatzek, S., van der Vossen, E. A., Jacobsen, E., Visser, R. G., Kamoun, S., and Vleeshouwers, V. G. 2015. Elicitin recognition confers enhanced resistance to Phytophthora infestans in potato. Nat. Plants 1:15034.

Ellis, J. 2006. Insights into nonhost disease resistance: Can they assist disease control in agriculture? Plant Cell 18:523-528.

Evangelisti, E., Govetto, B., Minet-Kebdani, N., Kuhn, M. L., Attard, A., Ponchet, M., Panabières, F., and Gourgues, M. 2013. The Phytophthora parasitica RXLR effector penetration-specific effector 1 favours Arabidopsis thaliana infection by interfering with auxin physiology. New Phytol. 199: 476-489.

Fankhauser, N., and Mäser, P. 2005. Identification of GPI anchor attachment signals by a Kohonen self-organizing map. Bioinformatics 21:1846-1852.

FAO. 2015. FAO Statistical Pocketbook 2015: World Food and Agriculture. Food and Agriculture Organization of the United Nations, Rome.

Fellbrich, G., Romanski, A., Varet, A., Blume, B., Brunner, F., Engelhardt, S., Felix, G., Kemmerling, B., Krzymowska, M., and Nurnberger, T. 2002. NPP1, a Phytophthora-associated trigger of plant defense in parsley and Arabidopsis. Plant J. 32:375-390.

Fu, Z. Q., and Dong, X. 2013. Systemic acquired resistance: Turning local infection into global defense. Annu. Rev. Plant Biol. 64:839-863.

Gaulin, E., Jauneau, A., Villalba, F., Rickauer, M., Esquerré-Tugayé, M. T. and Bottin, A. 2002. The CBEL glycoprotein of Phytophthora parasitica var-nicotianae is involved in cell wall deposition and adhesion to cellulosic substrates. J. Cell Sci. 115:4565-4575.

Gilbert, G. S., and Parker, I. M. 2016. The Evolutionary Ecology of Plant Disease: A Phylogenetic Perspective. Annu. Rev. Phytopathol. 54:549-578.

Govrin, E.M., and Levine, A. 2000. The hypersensitive response facilitates plant infection by the necrotrophic pathogen Botrytis cinerea. Curr. Biol. 10:751-757.

Gudesblat, G. E., Torres, P. S., and Vojnov, A. A. 2009. Stomata and pathogens: Warfare at the gates. Plant Signal. Behav. 4:1114-1116.

Hara-Nishimura, I., and Hatsugai, N. 2011. The role of vacuole in plant cell death. Cell Death Differ. 18:1298-1304.

Hippauf, F., Michalsky, E., Huang, R., Preissner, R., Barkman, T. J., and Piechulla, B. 2010. Enzymatic, expression and structural divergences among carboxyl $O$-methyltransferases after gene duplication and speciation in Nicotiana. Plant Mol. Biol. 72:311-330.

Höglund, S., Larsson, S., and Wingsle, G. 2005. Both hypersensitive and non-hypersensitive responses are associated with resistance in Salix viminalis against the gall midge Dasineura marginemtorquens. J. Exp. Bot. 56:3215-3222.

Huang, X., Li, Y., Zhang, X., Zuo, J., and Yang, S. 2010. The Arabidopsis LSD1 gene plays an important role in the regulation of low temperaturedependent cell death. New Phytol. 187:301-312.

Ippolito, A., Schena, L., and Nigro, F. 2002. Detection of Phytophthora nicotianae and $P$. citrophthora in citrus roots and soils by nested PCR Eur. J. Plant Pathol. 108:855-868.

Ito, M., Ohnishi, K., Hikichi, Y., and Kiba, A. 2015. Molecular chaperons and co-chaperons, Hsp90, RAR1, and SGT1 negatively regulate bacterial wilt disease caused by Ralstonia solanacearum in Nicotiana benthamiana. Plant Signal. Behav. 10:e970410.

Jones, J. D., and Dangl, J. L. 2006. The plant immune system. Nature 444: 323-329.

Kamoun, S., Klucher, K. M., Coffey, M. D., and Tyler, B. M. 1993. A gene encoding a host-specific elicitor protein of Phytophthora parasitica. Mol. Plant-Microbe Interact. 6:573-581. 
Karasov, T. L., Horton, M. W., and Bergelson, J. 2014. Genomic variability as a driver of plant-pathogen coevolution? Curr. Opin. Plant Biol. 18:24-30.

Kaurilind, E., Xu, E., and Brosché, M. 2015. A genetic framework for $\mathrm{H}_{2} \mathrm{O}_{2}$ induced cell death in Arabidopsis thaliana. BMC Genomics 16:837.

Kazan, K., and Lyons, R. 2014. Intervention of phytohormone pathways by pathogen effectors. Plant Cell 26:2285-2309.

Khatib, M., Lafitte, C., Esquerré-Tugayé, M.-T., Bottin, A., and Rickauer, M. 2004. The CBEL elicitor of Phytophthora parasitica var. nicotianae activates defence in Arabidopsis thaliana via three different signalling pathways. New Phytol. 162:501-510.

Kim, J. Y., Park, S. C., Hwang, I., Cheong, H., Nah, J. W., Hahm, K. S., and Park, Y. 2009. Protease inhibitors from plants with antimicrobial activity. Int. J. Mol. Sci. 10:2860-2872.

Krogh, A., Larsson, B., von Heijne, G., and Sonnhammer, E. L. 2001. Predicting transmembrane protein topology with a hidden Markov model: Application to complete genomes. J. Mol. Biol. 305:567-580.

Kushalappa, A. C., Yogendra, K. N., and Karre, S. 2016. Plant innate immune response: Qualitative and quantitative resistance. Crit. Rev. Plant Sci. 35:38-55.

Lacerda, A. F., Vasconcelos, E. A., Pelegrini, P. B., and Grossi de Sa, M. F. 2014. Antifungal defensins and their role in plant defense. Front. Microbiol. 5:116.

Lewis, L. A., Polanski, K., de Torres-Zabala, M., Jayaraman, S., Bowden, L., Moore, J., Penfold, C. A., Jenkins, D. J., Hill, C., Baxter, L., Kulasekaran, S., Truman, W., Littlejohn, G., Prusinska, J., Mead, A., Steinbrenner, J., Hickman, R., Rand, D., Wild, D. L., Ott, S., BuchananWollaston, V., Smirnoff, N., Beynon, J., Denby, K., and Grant, M. 2015. Transcriptional dynamics driving MAMP-triggered immunity and pathogen effector-mediated immunosuppression in Arabidopsis leaves following infection with Pseudomonas syringae pv tomato DC3000. Plant Cell 27: 3038-3064.

Li, B., Meng, X., Shan, L., and He, P. 2016. Transcriptional regulation of pattern-triggered immunity in plants. Cell Host Microbe 19:641-650.

Lo Presti, L., Lanver, D., Schweizer, G., Tanaka, S., Liang, L., Tollot, M., Zuccaro, A., Reissmann, S., and Kahmann, R. 2015. Fungal effectors and plant susceptibility. Annu. Rev. Plant Biol. 66:513-545.

Malinovsky, F. G., Fangel, J. U., and Willats, W. G. 2014. The role of the cell wall in plant immunity. Front. Plant Sci. 5:178

Marín, M., Uversky, V. N., and Ott, T. 2013. Intrinsic disorder in pathogen effectors: Protein flexibility as an evolutionary hallmark in a molecular arms race. Plant Cell 25:3153-3157.

Máximo, H. J., Dalio, R. J. D., Rodrigues, C. M., Breton, M., and Machado, M. A. 2017. Reference genes for RT-qPCR analysis in Citrus and Poncirus infected by zoospores of Phytophthora parasitica. Trop. Plant Pathol. 42:76-85

Mellersh, D.G., Foulds, I.V., Higgins, V.J., and Heath, M.C. 2002. $\mathrm{H}_{2} \mathrm{O}_{2}$ plays different roles in determining penetration failure in three diverse plant-fungal interactions. Plant J. 29:257-268.

Oßwald, W., Fleischmann, F., Rigling, D., Coelho, A. C., Cravador, A., Diez, J., Dalio, R. J., Horta Jung, M., Pfanz, H., Robin, C., Sipos, G., Solla, A., Cech, T., Chambery, A., Diamandis, S., Hansen, E., Jung, T., Orlikowski, L. B. Parke, J., Prospero, S., and Werres, S. 2014. Strategies of attack and defence in woody plant-Phytophthora interactions. For. Pathol. 44:169-190.

Panabieres, F., Ali, G. S., Allagui, M. B., Dalio, R. J. D., Gudmestad, N. C. Kuhn, M., Roy, S. G., Schena, L., and Zampounis, A. 2016. Phytophtora nicotianae diseases worldwide: New knowledge of long-recognised pathogen. Phytopathol. Mediterr. 55:20-40.

Qiang, X., Zechmann, B., Reitz, M. U., Kogel, K. H., and Schäfer, P. 2012. The mutualistic fungus Piriformospora indica colonizes Arabidopsis roots by inducing an endoplasmic reticulum stress-triggered caspasedependent cell death. Plant Cell 24:794-809.

Robert-Seilaniantz, A., Grant, M., and Jones, J. D. 2011. Hormone crosstalk in plant disease and defense: More than just jasmonate-salicylate antagonism. Annu. Rev. Phytopathol. 49:317-343.
Runyon, J. B., Mescher, M. C., and De Moraes, C. M. 2010. Plant defenses against parasitic plants show similarities to those induced by herbivores and pathogens. Plant Signal. Behav. 5:929-931.

Salzer, P., Corbière, H., and Boller, T. 1999. Hydrogen peroxide accumulation in Medicago truncatula roots colonized by the arbuscular mycorrhiza-forming fungus Glomus intraradices. Planta 208:319-325.

Shetty, N. P., Kristensen, B. K., Newman, M. A., Møller, K., Gregersen, P. L., and Jørgensen, H. J. L. 2003. Association of hydrogen peroxide with restriction of Septoria tritici in resistant wheat. Physiol. Mol. Plant Pathol. 62:333-346.

Siviero, A., Cristofani, M., Furtado, E. L., Garcia, A. A., Coelho, A. S., and Machado, M. A. 2006. Identification of QTLs associated with citrus resistance to Phytophthora gummosis. J. Appl. Genet. 47:23-28.

Song, M. Y., Kim, C. Y., Han, M., Ryu, H. S., Lee, S. K., Sun, L., He, Z., Seo, Y. S., Canal, P., Ronald, P. C., and Jeon, J. S. 2013. Differential requirement of Oryza sativa RAR1 in immune receptor-mediated resistance of rice to Magnaporthe oryzae. Mol. Cells 35:327-334.

Stam, R., Mantelin, S., McLellan, H., and Thilliez, G. 2014. The role of effectors in nonhost resistance to filamentous plant pathogens. Front. Plant Sci. 5:582.

Thomma, B. P., Nürnberger, T., and Joosten, M. H. 2011. Of PAMPs and effectors: The blurred PTI-ETI dichotomy. Plant Cell 23:4-15.

Thordal-Christensen, H., Zhang, Z., Wei, Y., and Collinge, D. B. 1997. Subcellular localization of $\mathrm{H} 2 \mathrm{O} 2$ in plants. $\mathrm{H} 2 \mathrm{O} 2$ accumulation in papillae and hypersensitive response during the barley-powdery mildew interaction. Plant J. 11:1187-1194.

Tripathy, B. C., and Oelmüller, R. 2012. Reactive oxygen species generation and signaling in plants. Plant Signal. Behav. 7:1621-1633.

Turner, J. G., Ellis, C., and Devoto, A. 2002. The jasmonate signal pathway. Plant Cell 14 (Suppl):S153-S164.

Verhage, A., van Wees, S. C., and Pieterse, C. M. 2010. Plant immunity: It's the hormones talking, but what do they say? Plant Physiol. 154:536-540.

Verma, V., Ravindran, P., and Kumar, P. P. 2016. Plant hormone-mediated regulation of stress responses. BMC Plant Biol. 16:86.

Vleeshouwers, V. G., van Dooijeweert, W., Govers, F., Kamoun, S., and Colon, L. T. 2000. The hypersensitive response is associated with host and nonhost resistance to Phytophthora infestans. Planta 210:853-864.

Wagner, S., Stuttmann, J., Rietz, S., Guerois, R., Brunstein, E., Bautor, J., Niefind, K., and Parker, J. E. 2013. Structural basis for signaling by exclusive EDS1 heteromeric complexes with SAG101 or PAD4 in plant innate immunity. Cell Host Microbe 14:619-630.

Wang, J., Wang, Y., Liu, X., Xu, Y., and Ma, Q. 2016. Microtubule polymerization functions in hypersensitive response and accumulation of $\mathrm{H}_{2} \mathrm{O}_{2}$ in wheat induced by the stripe rust. BioMed Rese. Int. 2016:7830768.

Wang, Y., Meng, Y., Zhang, M., Tong, X., Wang, Q., Sun, Y., Quan, J., Govers, F., and Shan, W. 2011. Infection of Arabidopsis thaliana by Phytophthora parasitica and identification of variation in host specificity. Mol. Plant Pathol. 12:187-201.

Xu, Z. S., Li, Z. Y., Chen, Y., Chen, M., Li, L. C., and Ma, Y. Z. 2012. Heat shock protein 90 in plants: Molecular mechanisms and roles in stress responses. Int. J. Mol. Sci. 13:15706-15723.

Zhang, Y., Lubberstedt, T., and Xu, M. 2013. The genetic and molecular basis of plant resistance to pathogens. J. Genet. Genomics 40:23-35.

Zhao, S., and Fernald, R.D. 2005. Comprehensive algorithm for quantitative real-time polymerase chain reaction. J. Comput. Biol. 12:1047-1064.

\section{AUTHOR-RECOMMENDED INTERNET RESOURCES}

The Arabidopsis Information Resource (TAIR) website: http://www.arabidopsis.org

Phytozome portal: https://phytozome.jgi.doe.gov/pz/portal.html

Primer3 Plus software:

http://www.bioinformatics.nl/cgi-bin/primer3plus/primer3plus.cgi

Real-time PCR Miner program: http://ewindup.info/miner/ 